\title{
Hydrogenation of chlorate ions by commercial carbon supported palladium catalysts_-a comparative study
}

\author{
Emőke Sikora ${ }^{1,2}$ (iD $\cdot$ Gábor Karacs ${ }^{3}$ - István Kocserha ${ }^{2,4} \cdot$ Gábor Muránszky $^{1,2}$. \\ Béla Fiser $^{1,2,5} \cdot$ Béla Viskolcz ${ }^{1,2} \cdot$ László Vanyorek $^{1,2}$
}

Received: 2 June 2020 / Accepted: 28 July 2020 / Published online: 10 August 2020

(c) The Author(s) 2020

\begin{abstract}
The chlorate elimination potential of three commercial activated carbon supported $10 \mathrm{wt} \%$ palladium catalysts (Cat-I, Cat-II and Cat-III) have been compared in heterogeneous catalytic hydrogenation. The physical-chemical properties of the catalysts were characterized by using high-resolution transmission electron microscopy, X-ray diffractometry, Fourier-transform infrared spectroscopy and $\zeta$ potential measurements. Chlorate reduction tests have been carried out by applying the same procedure and conditions in each case. The studied catalysts were active, but Cat-I and Cat-III showed higher activity, and eliminated $93 \%$ and $91 \%$ of chlorate, respectively. Reuse tests have also been carried out to compare the catalysts. Although Cat-I and Cat-III were shown almost equally high activity in the first cycle, the reuse tests showed that Cat-III could have a better applicability.
\end{abstract}

Keywords Catalytic hydrogenation $\cdot$ Chlorate elimination $\cdot$ Activated carbon $\cdot \mathrm{Pd}$ catalyst

\section{Introduction}

Chlorate as water pollutant can be found in surface and groundwater as well, and it enters the water as a result of human activity [1]. There are many sources of potential release of chlorate to the environment [2]. It can be formed during the decomposition of chlorine dioxide, which is used as water disinfectant, but also as bleaching

Emőke Sikora

emoke.sikora@gmail.com

1 Institute of Chemistry, University of Miskolc, Miskolc, Hungary

2 Higher Education Industry Cooperation Centre, University of Miskolc, Miskolc, Hungary

3 MTA-ME Materials Science Research Group, University of Miskolc, Miskolc, Hungary

4 Institute of Ceramics and Polymer Engineering, University of Miskolc, Miskolc, Hungary

5 Ferenc Rákóczi II. Transcarpathian Hungarian Institute, Beregszász, Transcarpathia, Ukraine 
agent for cellulose, paper pulp, flour, oils and cleaning and detanning leather [3-5]. The use of chlorine dioxide has increased in the last century, because, unlike chlorine, it does not lead to the formation of significant levels of additional harmful disinfection by-products (DBPs) such as trihalomethanes (THMs) and haloacetic acids (HAAs) [6, 7]. However, chlorate formation is problematic and as a pollutant of the environment needs to be handled. Furthermore, its appearance in industrial processes could also cause complications and deteriorate the production, such as in membrane cell electrolysis [8].

According to the guidelines of the World Health Organization, $700 \mu \mathrm{g} / \mathrm{L}$ is the acceptable upper limit for chlorate concentration in drinking water [9]. Several methods for removing chlorate from water or brine have been already investigated, such as adsorption with granular activated carbon [10], thermal treatment with $\mathrm{HCl}$ and UV [11], thermal hydrochloric acid treatment in combination with a reducing agent [12], or biochemical reduction method [13]. However, there is no standardized procedure for the removal $[14,15]$. The most common technologies used to treat oxyanion-contaminated water are ion-exchange, reverse osmosis and adsorption [16, 17]. Although these methods are effective, but they only separate the contaminants, by either trapping them in a resin matrix, or concentrating in a waste brine without elimination $[18,19]$. Destructive treatments such as catalytic hydrogenation may be preferred to convert oxyanions into less toxic or harmless end products (e.g. $\mathrm{Br}^{-}$, $\mathrm{Cl}^{-}$and $\mathrm{N}_{2}$ ) [20-22]. Catalytic procedures are advantageous, because their energy demand is lower and they can initiate the degradation of contaminants in water without waste, or by-products [17].

Catalytic hydrogenation of perchlorate and bromate has been extensively investigated [19, 23-27], in contrast to that, catalytic chlorate hydrogenation has not been examined in too many cases. Kuznetsova et al. [28] prepared Ir/AC (Ir/active carbon) catalysts and successfully used them in chlorate hydrogenation experiments. The best catalyst was able to achieve $100 \%$ chlorate conversion and contained $5 \mathrm{wt} \%$ Ir [28].

The efficiency of catalysts in the catalytic hydrogenation of halogen oxyanions can be increased with rhenium [29]. Elements of the platinum group (Ir, Rh, Pt) were used as active metals for the catalysis, while silica, titanium dioxide and activated carbon were tested as supports. In these experiments, the activity of monometallic catalysts (Ir, Rh, Pt or Re) was lower. However, when 15 or $25 \mathrm{wt} \%$ of the precious metals were replaced by Re, the activity of the catalysts increased [29].

$\mathrm{Pd}, \mathrm{Ru}, \mathrm{Rh}$ and $\mathrm{Pt}$ were also tested in combination with activated carbon and alumina supports as potential catalysts in chlorate and perchlorate reduction [20,30]. For both carrier, the catalyst with rhodium nanoparticles had the highest catalytic activity [20, 30]. The performance of $\mathrm{Ru} / \mathrm{AC}, \mathrm{Rh} / \mathrm{AC}$ and $\mathrm{Pd} / \mathrm{AC}$ catalysts was also compared and the rhodium was the fastest, while the ruthenium was the slowest in terms of reduction [30].

Despite the fact that chlorate reduction by hydrogen in the presence of a catalyst will lead to the formation of benign species, water and chloride ions [17], this process is not over-examined and there are still room for improvements. To pave the way of the design of novel catalysts successfully applicable in chlorate hydrogenation, first of all, the performance of promising commercial catalysts should be 
compared. Therefore, three commercially available activated carbon supported Pd (10 wt $\%$ ) catalysts have been studied. Their chlorate elimination potential has been compared in heterogeneous catalytic hydrogenation. Reuse tests were also carried out to get more information about the activity of the catalysts.

\section{Experimental}

Potassium chlorate $\left(\mathrm{KClO}_{3}\right.$, from Aldrich), potassium iodide, (KI, from Merck), concentrated (37 wt $\%$ ) hydrochloric acid ( $\mathrm{HCl}$, from $\mathrm{VWR})$, hydrogen and nitrogen (5.0 and 4.5 purity, from Messer Ltd.) were used during the chlorate hydrogenation experiments. The tested catalysts were activated carbon supported $10 \mathrm{wt} \% \mathrm{Pd}$ systems purchased from Sigma-Aldrich Co. (cat.num.: 205699, Cat-I), N.E. Chemcat Co. (cat.num.: chcq10, Cat-II) and Alfa Aesar Chemical Co. Ltd (cat.num.: 44696, Cat-III).

To characterize the catalysts high-resolution transmission electron microscopy was applied (HRTEM), by using the FEI Technai G2 equipment (electron source W emitter, $200 \mathrm{kV}$ ). Sample preparation was carried out by dropping aqueous suspension of the catalyst samples on 300 mesh copper grids (lacey carbon, Ted Pella Inc.). The diameters of the nanoparticles were measured on the HRTEM images, based on the original scale bar using the ImageJ software. X-ray diffractometry (XRD) was also performed by using a Bruker D8 Advance diffractometer $\left(\mathrm{Cu} \mathrm{K}_{\alpha}\right.$ source, $40 \mathrm{kV}$ and $40 \mathrm{~mA}$, with Vantec 1 detector) to identify and quantify the palladium nanoparticles. The functional groups on the surface of the activated carbon supports were studied by using Fourier-transform infrared spectroscopy (FTIR). This was carried out by using a Bruker Vertex 70 equipment in transmission mode with $\mathrm{KBr}$ pellets (10 mg sample in $250 \mathrm{mg} \mathrm{KBr}$ ) and the interval was $400-4000 \mathrm{~cm}^{-1}$, while the resolution was $4 \mathrm{~cm}^{-1}$ with $16 \mathrm{~min}^{-1}$ scan rate. Electro kinetic potentials were also measured in aqueous phase ( $5 \mathrm{mg}$ sample in $100 \mathrm{ml}$ dist. water) by using a Malvern Zeta Sizer Nano Zs. Laser Doppler Micro-electrophoresis technique was applied, and the electrokinetic potential values were calculated based on the electrophoretic mobilities by using the Henry equation.

Hydrogenation of the $\mathrm{ClO}_{3}{ }^{-}$ions was performed in aqueous solution of potassium-chlorate $\left(200 \mathrm{mg} \mathrm{dm}^{-3}\right)$. The solution was placed in a side-inlet gas washing bottle with fritted disc and the temperature was set to $80{ }^{\circ} \mathrm{C}$ by using a Julabo circulator. Gas supply was provided (40 standard $\mathrm{cm}^{3}$ nitrogen and 100 standard $\mathrm{cm}^{3}$ hydrogen), while the amount of catalyst was $200 \mathrm{mg}$ in all measurements. The experiments were run for $3 \mathrm{~h}$ and sampling was carried out after $0,5,15,30,45,60$, $90,120,150$, and, $180 \mathrm{~min}$.

Chlorate concentration in the samples was determined by using the UV-6300PC spectrophotometer at $351 \mathrm{~nm}$ wavelength, applying redox reaction between iodide and chlorate ions as follows:

$$
\mathrm{KClO}_{3}+6 \mathrm{KI}+6 \mathrm{HCl} \rightarrow 3 \mathrm{H}_{2} \mathrm{O}+3 \mathrm{I}_{2}+7 \mathrm{KCl}
$$


The colour of the solution changed as the iodine formed during the reaction and this can be associated with the concentration change of the chlorate. For each sample $(1 \mathrm{~mL}), 0.1 \mathrm{~g}$ potassium iodide and $1 \mathrm{~mL}$ hydrochloric acid were added and then it was diluted to $50 \mathrm{ml}$ with distilled water. The quantity of iodine was measured by using a UV-VIS spectrophotometer. This spectrophotometric method was calibrated by using potassium-chlorate solutions with different concentrations $(0,50,100,150$ and $200 \mathrm{mg} \mathrm{dm}^{-3}$ ).

\section{Results and discussion}

\section{Characterization of the catalysts}

The palladium nanoparticles of the studied catalyst are visible on the HRTEM images (Fig. 1a-c). The particles are quite small in each case.

In case of the catalyst Cat-I, the size distribution is slightly heterodisperse as the diameter of the particles varying between 3.4 and $18.9 \mathrm{~nm}$. The mean size was $7.6 \pm 3.3 \mathrm{~nm}$, with relatively high standard deviation which means, that the dispersibility of Pd particles is not homogeneous and this is visible on the histogram as well (Fig. 1d). It is visible on the HRTEM image of Cat-II catalyst that the activated carbon surface is abundantly covered by palladium nanoparticles. The average particle size within this sample was $3.7 \pm 1.0 \mathrm{~nm}$, while the minimum and maximum were

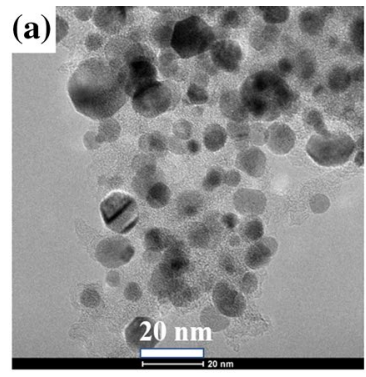

(d)

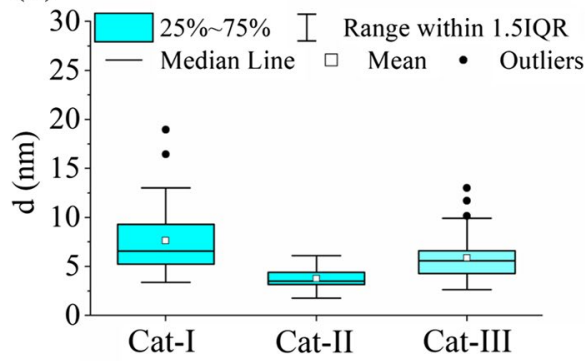

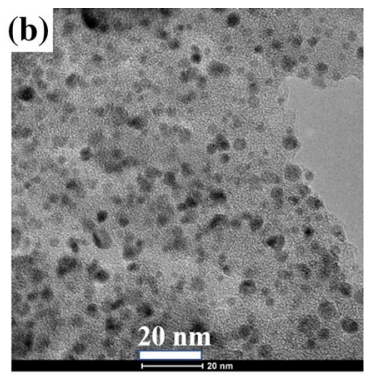
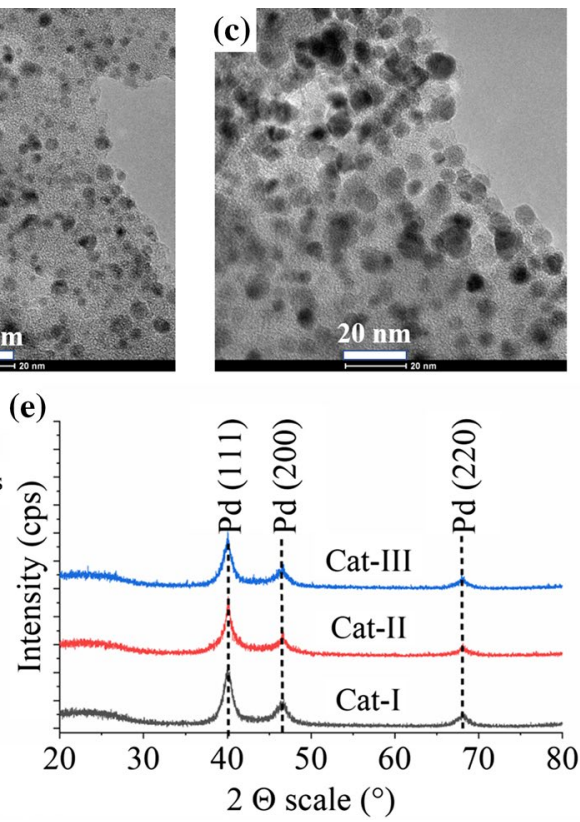

Fig. 1 HRTEM images of the studied commercially available catalysts: Cat-I (a), Cat-II (b) and Cat-III (c). These are activated carbon based $10 \mathrm{wt} \% \mathrm{Pd}$ systems. Particle-size distributions (d) and XRD patterns (e) have also been measured and compared 
1.8 and $6.1 \mathrm{~nm}$, respectively (Fig. 1d). The size distribution is nearly homogeneous as the particle size in the first (Q1) and third quartile (Q3) is 3.5 and $4.4 \mathrm{~nm}$, respectively (Table 1). The particle-size distribution of catalyst of Cat-III, is not as heterodisperse as of Cat-I (Fig. 1d). However, the mean diameter of the Pd nanoparticles is bigger $(5.9 \pm 2.0 \mathrm{~nm})$ and the particle size varied between a wider $(2.6$ and $13.0 \mathrm{~nm})$ range compare to Cat-II (Table 1).

The crystalline phases of the palladium within the catalyst samples were characterized by XRD (Fig. 1e). In each case three reflexion peaks were identified at $40.1^{\circ}$, $46.6^{\circ}$ and $68.3^{\circ} 2 \Theta$ degrees, which belongs to the $\mathrm{Pd}(111), \mathrm{Pd}(200)$ and $\mathrm{Pd}(220)$ phases. Thus, in each catalyst, the total amount of palladium is in metallic (elemental) phase and there is no significant difference between them in terms of their $\mathrm{Pd}$ phases.

High dispersibility of the catalysts in aqueous media is very important as the accessibility of the catalytically active phase of the catalysts by the reactant molecules depends heavily on the dispersibility of the catalysts and thus, influence the catalytic activity. The dispersibility is increasing by the surface polarity of the catalyst. Thus, the presence of oxygen-containing functional groups (hydroxyl-, carboxyl-groups etc.) is crucial to achieve high catalytic activity. Hydroxyl- and carboxyl groups can be deprotonated, depending on the $\mathrm{pH}$ of the environment, and thus, the surface charge will be negative, which will provide dispersion stability in aqueous phase. In the case of the studied catalysts and the investigated chlorate elimination process the presence of the oxygen containing functional groups on the surface of the activated carbon support can be pivotal, and thus, this was verified by using FTIR. Absorption bands at $3418 \mathrm{~cm}^{-1}, 3439 \mathrm{~cm}^{-1}, 3446 \mathrm{~cm}^{-1}$ have been located on the infrared spectra of catalyst Cat-I, Cat-II and Cat-III. These can be associated with the stretching of the surface -OH groups. Peaks at $2841 \mathrm{~cm}^{-1}$ and $2915 \mathrm{~cm}^{-1}$ were also identified, which are the symmetric and asymmetric stretching modes of the $-\mathrm{CH}_{2}$. All spectra have a band at $1630 \mathrm{~cm}^{-1}$, which indicates the $\nu \mathrm{C}=\mathrm{C}$ vibration. The Cat-III has a peak at $1392 \mathrm{~cm}^{-1}$ which does not appear on the other spectra and it corresponds to the $\beta \mathrm{OH}$ vibration mode.

The presence of oxygen containing functional groups has been verified and thus, negative surface charge is expected as the deprotonation of the dissociable functional groups $(-\mathrm{OH})$ will lead to that. The $\mathrm{pH}$ of the aqueous solution of the catalysts $(5 \mathrm{mg}$ in $100 \mathrm{ml}$ distilled water) has also been measured and in the case of Cat-I and Cat-II it was 6.98 and 6.90, respectively, while for Cat-III it was slightly basic (7.08). However, the difference is not significant and thus, their electrokinetic potential can be

Table 1 Analysis of the size distribution of the palladium nanoparticles in case of the studied commercially available catalysts: Cat-I, Cat-II and Cat-III

\begin{tabular}{lllllll}
\hline & Mean $(\mathrm{nm})$ & Min. $(\mathrm{nm})$ & Max. $(\mathrm{nm})$ & Q1 $(\mathrm{nm})$ & Median $(\mathrm{nm})$ & Q3 $(\mathrm{nm})$ \\
\hline Cat-I & $7.6 \pm 3.3$ & 3.4 & 18.9 & 5.2 & 6.6 & 9.3 \\
Cat-II & $3.7 \pm 1.0$ & 1.8 & 6.1 & 3.2 & 3.5 & 4.4 \\
Cat-III & $5.9 \pm 2.0$ & 2.6 & 13.0 & 4.3 & 5.6 & 6.6 \\
\hline
\end{tabular}


compared. The $\zeta$ potential of the catalysts was measured, and negative values were experienced in each case (Fig. 2B). The most negative $\zeta$-potential $(-25.1 \mathrm{mV})$ was measured in case of Cat-III. The $\zeta$-potential values of Cat-I and Cat-II are higher and quite close to each other $-19.2 \mathrm{mV}$ and $-21.2 \mathrm{mV}$, respectively.

\section{Catalytic hydrogenation of chlorate ions}

Chlorate elimination was carried out by using the tested catalysts in heterogeneous catalytic hydrogenation. The initial chlorate concentration was $200 \mathrm{mg} \mathrm{dm}^{-3}$ in each case.

The most intensive effect on the chlorate ion concentration was achieved by CatI, which reduced the chlorate concentration to $14.8 \mathrm{mg} \mathrm{dm}^{-3}$ and thus, $93 \%$ of the initial $\mathrm{ClO}_{3}{ }^{-}$ions converted to chloride. Cat-III was able to reduce the $\mathrm{ClO}_{3}{ }^{-}$concentration by $91 \%$, while Cat-II was only able to reach $60.4 \mathrm{mg} \mathrm{dm}^{-3}$ which is a $70 \%$ reduction (Fig. 3a). The reusability of the catalysts was also compared. Catalysts were examined in reuse tests and three cycles have been performed (Fig. 3b). The catalysts were regenerated at $400{ }^{\circ} \mathrm{C}$ in hydrogen atmosphere after each cycle. The activity of Cat-I and Cat-III significantly decreased after the first cycle and in the second cycle only $81 \%$ and $78 \%$ of the chlorate ions eliminated by them, respectively. The chlorate reduction was also decreased when Cat-II was used and in the second cycle only $63 \%$ was achieved. However, in the third cycle the activity of CatII and Cat-III is not changed significantly, the decrement was only 4 and $1 \%$, respectively. In contrast to this, Cat-I showed a steady decline $(93 \%, 81 \%, 63 \%)$ during the reuse tests.

All in all, the three tested commercially available catalysts are applicable in catalytic chlorate reduction. Although Cat-I and Cat-III were shown almost equally high activity in the first cycle, the reuse tests showed that Cat-III could have a better applicability as after repeated usage and regeneration it keeps higher catalytic activity in chlorate reduction than the other two tested catalysts.

(a)

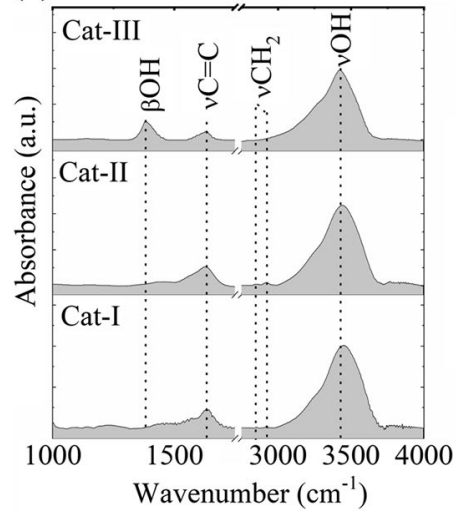

(b)

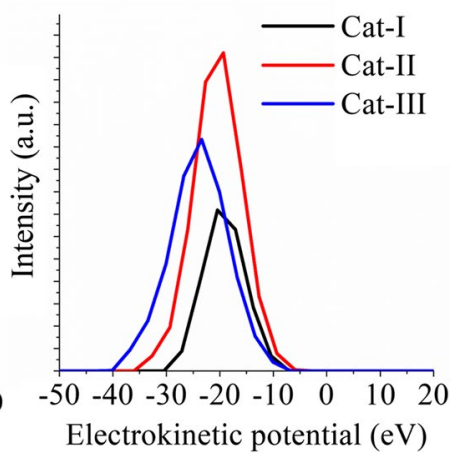

Fig. 2 FTIR spectra (a) and electro-kinetic potential distributions (b) of the studied activated carbon supported palladium catalysts: Cat-I, Cat-II, Cat-III 

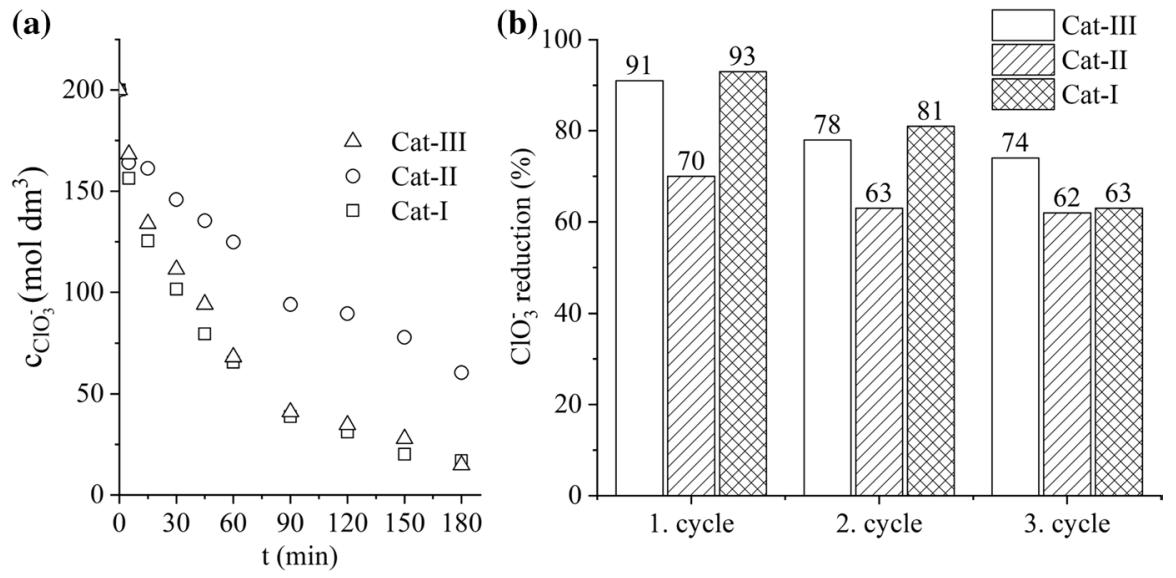

Fig. 3 The studied catalyst (Cat-I, Cat-II and Cat-III) were compared in terms of their activity in chlorate reduction. The catalytic tests have been carried out and the chlorate concentration change vs. time of hydrogenation (a) is plotted. Reuse tests have also been performed in three cycles (b)

\section{Conclusion}

The chlorate elimination potential of three commercial activated carbon supported $10 \mathrm{wt} \%$ palladium catalysts have been compared in heterogeneous catalytic hydrogenation. The catalysts were activated in hydrogen atmosphere before the hydrogenation tests. The samples were characterized by high-resolution transmission electron microscopy (HRTEM), X-ray diffractometry (XRD), Fouriertransform infrared spectroscopy (FTIR) and Zeta potential measurements. In each case, the activated carbon supports are abundantly covered by elemental palladium nanoparticles with high dispersibility. The mean particle size was 7.6, 3.7 and $5.9 \mathrm{~nm}$, for Cat-I, Cat-II and Cat-III. In each catalyst, the total amount of palladium is in elemental phase. The presence of oxygen containing functionals groups on the surface of the activated carbon supports has been verified. The electrokinetic potential of the catalysts was measured and negative Zeta potential was experienced in each case as it was be expected based on the functional groups on the surface. The most negative $\zeta$-potential $(-25.1 \mathrm{mV})$ was measured in case of Cat-III. The $\zeta$-potential values of Cat-I and Cat-II are lower and quite close to each other $-19.2 \mathrm{mV}$ and $-21.2 \mathrm{mV}$, respectively. Each catalyst was active during the chlorate reduction experiments. Although Cat-I and Cat-III were shown almost equally high activity in the first cycle, the reuse tests showed that Cat-III could have a better applicability as after repeated usage and regeneration $(91 \%$, $78 \%, 74 \%)$ it has higher catalytic activity in chlorate reduction than the other two tested catalysts.

Acknowledgements Open access funding provided by University of Miskolc. This research was supported by the European Union and the Hungarian State, co-financed by the European Regional Development Fund in the framework of the (Grant No. GINOP-2.3.4-15-2016-00004) project, aimed to promote the cooperation between the higher education and the industry. 


\section{Compliance with ethical standards}

Conflict of interest On behalf of all authors, the corresponding author states that there is no conflict of interest.

Open Access This article is licensed under a Creative Commons Attribution 4.0 International License, which permits use, sharing, adaptation, distribution and reproduction in any medium or format, as long as you give appropriate credit to the original author(s) and the source, provide a link to the Creative Commons licence, and indicate if changes were made. The images or other third party material in this article are included in the article's Creative Commons licence, unless indicated otherwise in a credit line to the material. If material is not included in the article's Creative Commons licence and your intended use is not permitted by statutory regulation or exceeds the permitted use, you will need to obtain permission directly from the copyright holder. To view a copy of this licence, visit http://creativecommons.org/ licenses/by/4.0/.

\section{References}

1. Logan BE (1998) A review of chlorate- and perchlorate-respiring microorganisms. Bioremediat J 2:69-79. https://doi.org/10.1080/10889869891214222

2. Lakshmanan S, Yung YL (2019) Reduction of chlorate and regeneration of activated carbon used for chlorate adsorption. Blue-Green Syst 1:72-85. https://doi.org/10.2166/bgs.2019.193

3. WHO (2005) Chlorite and chlorate in drinking- water. WHO Guidel Drink water Qual 31:29-44

4. Boano F, Fiore S, Revelli R (2016) Chlorate formation in water distribution systems: a modeling study. J Hydroinform 18:115-125. https://doi.org/10.2166/hydro.2015.079

5. Stanford BD, Pisarenko AN, Snyder SA, Gordon G (2011) Perchlorate, bromate, and chlorate in hypochlorite solutions: guidelines for utilities. J Am Water Works Assoc 103:71-83. https://doi. org/10.1002/j.1551-8833.2011.tb11474.x

6. Yang X (2015) Understanding the role of chlorine dioxide as pre-oxidant and disinfectant. J Civ Environ Eng 5:1. https://doi.org/10.4172/2165-784x.1000172

7. Righi E, Bechtold P, Tortorici D et al (2012) Trihalomethanes, chlorite, chlorate in drinking water and risk of congenital anomalies: a population-based case-control study in Northern Italy. Environ Res 116:66-73. https://doi.org/10.1016/j.envres.2012.04.014

8. Brinkmann T, Giner Santonja G, Schorcht F et al (2014) Best available techniques reference document for the production of Chlor-alkali. Joint Research Centre, Ispra. https://doi.org/10.2791/13138

9. World Health Organization (2014) Guidelines for drinking-water quality: fourth edition incorporating the first addendum. WHO, Geneva

10. Gonce N, Voudrias EA (1994) Removal of chlorite and chlorate ions from water using granular activated carbon. Water Res 28:1059-1069. https://doi.org/10.1016/0043-1354(94)90191-0

11. Lai P, Szymanski S, Christensen NL (1979) Removal of chlorate from electrolytic cell anolyte. US4,169,77

12. Moore SH, Dotson RL (1983) Process for the removal of chlorate and hypochlorite from spent alkali metal chloride brines. US4609472

13. Korenkov VN, Romanenko VI, Kuznetsov SI, Voronov J V (1976) Process for purification of industrial waste waters from perchlorates and chlorates. US3,943,055

14. Alfredo K, Stanford BEN, Roberson JA, Eaton A (2015) Chlorate challenges for water systems. J Am Water Work Assoc 107:187-196

15. Garcia-Villanova RJ, Oliveira Dantas Leite MV, Hernández Hierro JM et al (2010) Occurrence of bromate, chlorite and chlorate in drinking waters disinfected with hypochlorite reagents. Tracing their origins Sci Total Environ 408:2616-2620. https://doi.org/10.1016/j.scitotenv.2010.03.011

16. Gunatilake SK (2015) Methods of removing heavy metals from industrial wastewater. J Multidiscip Eng Sci Stud 1:12-18 
17. Yin YB, Guo S, Heck KN et al (2018) Treating water by degrading oxyanions using metallic nanostructures. ACS Sustain Chem Eng 6:11160-11175. https://doi.org/10.1021/acssuschemeng.8b020 70

18. Weidner E, Ciesielczyk F (2019) Removal of hazardous oxyanions from the environment using metal-oxide-based materials. Materials (Basel) 12:927. https://doi.org/10.3390/ma12060927

19. Hurley KD, Shapley JR (2007) Efficient heterogeneous catalytic reduction of perchlorate in water. Environ Sci Technol 41:2044-2049. https://doi.org/10.1021/es0624218

20. Chen X, Huo X, Liu J et al (2017) Exploring beyond palladium: catalytic reduction of aqueous oxyanion pollutants with alternative platinum group metals and new mechanistic implications. Chem Eng J 313:745-752. https://doi.org/10.1016/j.cej.2016.12.058

21. Chaplin BP, Reinhard M, Schneider WF et al (2012) Critical review of Pd-based catalytic treatment of priority contaminants in water. Environ Sci Technol 46:3655-3670. https://doi.org/10.1021/es204 $087 q$

22. Srinivasan R, Sorial GA (2009) Treatment of perchlorate in drinking water: a critical review. Sep Purif Technol 69:7-21. https://doi.org/10.1016/j.seppur.2009.06.025

23. Mahmudov R, Shu Y, Rykov S et al (2008) The reduction of perchlorate by hydrogenation catalysts. Appl Catal B Environ 81:78-87. https://doi.org/10.1016/j.apcatb.2007.11.039

24. Chen $\mathrm{H}, \mathrm{Xu} \mathrm{Z}$, Wan $\mathrm{H}$ et al (2010) Aqueous bromate reduction by catalytic hydrogenation over $\mathrm{Pd} /$ $\mathrm{Al}_{2} \mathrm{O}_{3}$ catalysts. Appl Catal B Environ 96:307-313. https://doi.org/10.1016/j.apcatb.2010.02.021

25. Palomares AE, Franch C, Yuranova T et al (2014) The use of Pd catalysts on carbon-based structured materials for the catalytic hydrogenation of bromates in different types of water. Appl Catal B Environ 146:186-191. https://doi.org/10.1016/j.apcatb.2013.02.056

26. Restivo J, Soares OSGP, Órfão JJM, Pereira MFR (2017) Catalytic reduction of bromate over monometallic catalysts on different powder and structured supports. Chem Eng J 309:197-205. https:// doi.org/10.1016/j.cej.2016.10.025

27. Soares OSGP, Freitas CMAS, Fonseca AM et al (2016) Bromate reduction in water promoted by metal catalysts prepared over faujasite zeolite. Chem Eng J 291:199-205. https://doi.org/10.1016/j. cej.2016.01.093

28. Kuznetsova LI, Kuznetsova NI, Koscheev SV et al (2012) Carbon-supported iridium catalyst for reduction of chlorate ions with hydrogen in concentrated solutions of sodium chloride. Appl Catal A Gen 427-428:8-15. https://doi.org/10.1016/j.apcata.2012.03.024

29. Rosei R, Conte L, Trovarelli A et al (2016) Method for the catalyzed reduction of halogen oxianions in aqueous solutions. US 2016/0347634

30. Liu J, Chen X, Wang Y et al (2015) Mechanism and mitigation of the decomposition of an oxorhenium complex-based heterogeneous catalyst for perchlorate reduction in water. Environ Sci Technol 49:12932-12940. https://doi.org/10.1021/acs.est.5b03393

Publisher's Note Springer Nature remains neutral with regard to jurisdictional claims in published maps and institutional affiliations. 